\title{
INVESTIGATION OF PLANT AND EQUIPMENT OPERATORS IN BUILDING CONSTRUCTION PROJECTS IN SRI LANKA
}

\author{
WAIDYASEKARA K.G.A.S. ${ }^{1}$, RIDMIKA K.I. ${ }^{2}$, SANDAGOMIKA N.M.G.H. ${ }^{3}$ \& KONARA A.N. ${ }^{4}$ \\ 1,2,3,4University of Moratuwa, Katubedda, Sri Lanka \\ 1anuradha@uom.lk, 2isuridmika@gmail.com, 3helaminisandagomika94@gmail.com, ${ }^{4} a$ shendranik@gmail.com
}

\begin{abstract}
The construction industry, which is a labour intensive and skill development of the industry would yield both economic and social returns to the national economy. Among other occupational categories, there is a significant demand for the plant and equipment (P\&E) operators in the construction industry. Nevertheless, limited numbers of research are available on the said area. Hence, the aim of this paper is to investigate the status of P\&E operators in Sri Lankan building construction projects. Accordingly, this study encompassed a qualitative research approach, and six semi-structured expert interviews were conducted as the data collection tool. The study revealed that mainly two categories of P\&E as moveable and immovable and further identified subcategories under each. Based on the results, occupational map was developed for the P\&E operators in building construction projects in Sri Lanka. Furthermore, the study revealed that technical and mechanical skills as an essential input for an efficient P\& E operator. Moreover, the paper discussed issues with P \& E operators. Accordingly, inconsistency, taking long leave, poor health conditions, less experience, and less motivation were identified as prominent issues.
\end{abstract}

Keywords: Building Construction; Issues; Occupational Map; Skills; Plant and Equipment (P\&E) Operators

\section{Introduction}

The construction industry, being one of the most important industry and a major engine of global eco-nomic growth, forms the foundation for most countries' strategic initiatives (Aiyetan \& Dillip, 2018). The project execution in construction industry is a process which is performed by different types of employees (Fernando, Fernando, \& Gunarathna, 2016). Therefore, construction industry can be identified as a labourintensive sector (Alaghbari, et al, 2019). Moreover, the construction industry heavily depends on human resources, and low-skilled employees account for the majority of workers (Ceric \& Ivic, 2020). Nevertheless, with technological advancement, there are many different types of plant and equipment (P\&E) used within construction, and each is designed to carry out specific jobs and serves a particular function (Kamaruddin, Mohammad, \& Mahbub, 2016). Therefore, the employee category of P\&E operators plays a vital role in construction industry (Manikandan, et al., 2018). Heavy machineries are using to dig, lift and move materials in construction sites. Plant operators usually specialise in one type of equipment, such as an excavator or giant crane (Silva, Warnakulasuriya, \& Arachchige, 2018). Accordingly, those P\&E operators have to encompass specific set of skills (Naskoudakis \& Petroutsatou, 2016; Silva et al., 2018).

Nevertheless, there is a shortage of skilled workers in construction industry which has been a critical concern all over the world (Prajeesh \& Sakthivel, 2016). The supply of the P\&E operators in Sri Lankan construction industry typically lags in terms of the number and the quality of the P\&E operators (Chandasiri, 2017; Fernando et al., 2016). The Sri Lankan society, experiencing high economic growth and increasing level of education, does not highly value construction-related occupants (International Labour Organisation [ILO], 2017). This can be identified as one of major concerns in the lesser supply of the occupants in construction industry. The absence of required skills and competencies among occupants causes the lower quality of the construction workers (Prajeesh \& Sakthivel, 2016). This skill shortages can be typically identified in the category of P\&E operators even in Sri Lanka (Silva et al., 2018). Therefore, this study aimed to investigate P\&E operators in building construction projects in Sri Lanka as there is no 
significant research which has been undertaken separately for this occupation category. To achieve this aim, three objectives were formed and followed; developing an occupational map for P\&E operators, identifying required skills and finally investigating the issues in occupational category of P\&E operators in building construction projects in Sri Lanka.

\section{Literature}

\subsection{CONSTRUCTION INDUSTRY}

Construction industry plays an important role in every nation as it fulfils the all the requirement of having a built environment (Feng, et al., 2015). Sri Lankan construction industry plays a vital role encompassing different types of construction activities (Anuruddika \& Sandanayake, 2015). Annual report of Central Bank of Sri Lanka (2019) has identified eight (8) types of construction activities: construction of buildings, construction of roads and railways, construction of other civil engineering projects, demolition and site preparation, electrical, plumbing and other construction installation activities, building completion and finishing, and other specialized construction activities. It does not only form the physical assets but also contributes to the national economy, provides employment opportunities and upgrades the quality of community life (Taofeeq,et al., 2020).

The construction industry has a capacity to generate employment opportunities to thousands of unskilled, semi- skilled and skilled workforces. In Sri Lanka, the construction industry has given $8.5 \%$ of total employment opportunities in 2019 according to the Annual report of Central Bank of Sri Lanka (2019). The estimated total employment in construction industry is around 438,316 in 2017 and expected to increase up to 484,606 and 622,868 respectively in 2018 and 2022 (Chandasiri, 2017). As stated by Gurmu and Aibinu (2017), technology is being improved daily, P\&E are also developed but the construction sector remains still as labour intensive.

\subsection{PLANT AND EQUIPMENT OPERATORS}

Modern construction P\&E plays an important role where business objectives are rigorously time and margin driven in the construction industry (Prajeesh \& Sakthivel, 2016). Modern construction equipment is expeditious and stable, and it has high-quality control systems built into it as it has progressed over time in the construction industry. The proper use of this P\&E enhances the economy, quality, safety, speed, and timely completion of the building projects (Naskoudakis \& Petroutsatou, 2016). P\&E operators in construction industry are responsible for operating heavy machinery and equipment used in construction site. Under the umbrella of huge technical advancement, there are different types of P\&E which are used in construction industry. In every construction P\&E is built to perform a specific function. Selection of different types of $\mathrm{P} \& \mathrm{E}$ depend on the size of the work and economy of the project. These make construction process easier and faster. These plants come in a variety of sizes and perform a variety of tasks. Excavators, backhoes, front shovels, graders, loaders, and tractors are among the most commonly utilized plants in construction projects. Excavators are described by Komissarov, et al. (2016) as being one of the massive construction equipment that consists of a stick, boom, bucket, and cab on a rotating platform. A backhoe plant can be used for excavating and is also known as a rear actor or back actor. It has a digging bucket on the end of a two-part articulated arm and is also used for excavating. As a result, it also can apply high tooth pressure, allowing it to extract stiff material that would otherwise be impossible to excavate with a dragline. Furthermore, according to Frankel (2003), backhoes are employed for a variety of tasks, including having to clean up debris on worksites, smoothing out uneven surfaces, excavating holes, and digging trenches. Further, cranes, forklift trucks, beakers, compacters, concreting plants, earthmoving plants and piling plants are some of the main plants and equipment utilised in the Sri Lankan construction industry (Basnayake \& Premathilaka, 2015).

\subsection{WORKPLACE SKILLS OF PLANT AND EQUIPMENT OPERATORS}

Skills are defined as the things learned to be able to carry out one or more job functions while competencies incorporate a skill, but are more than the skills, they include abilities and behaviours, as well as the knowledge that is fundamental to the use of a skill (Detsimas, et al., 2016). Since each P\&E operators handle specific plant or equipment, these operators have to encompass a different set of skills in handling those plants or equipment. As well as in other occupants in other industries and the construction industry, P\&E operators have to equip with those skills to perform their duty properly. Plant or equipment operating skills, safe working skills, interpersonal skills, communication skills, team working skills, organising skills, 
reading and interpretational skills are set of skills expected from P \&E operators (Basnayake \& Premathilaka, 2015).

The absence of required skills and competencies among occupants negatively impacts the quality of the construction occupants (Detsimas et al., 2016). It has been recorded that only $14 \%$ of occupants had proper training in the construction industry (Chandasiri, 2017). The Skill Development Project (SDP) has joined with TVEC to resolve problems of mismatching training programmes with current market demand, duplication of training provided by institutions and non-availability of unified standards (Jayawardena, Senevirathne, \& Jayasena, 2008). There are many courses which are offered by TVEC targeting the P\&E operators in the construction industry. As a predominantly labour-intensive industry, the construction sector obtains huge benefits from skilled workers. In this regard, effective training programmes are of paramount importance to enhance the skill levels of workers (Detsimas et al., 2016; Jayawardena et al., 2008).

\subsection{ISSUES WITH PLANT AND EQUIPMENT OPERATORS}

Issues of shortage of human capital and skill mismatching issues are typical in the Sri Lankan industry (Silva et al., 2018). The Sri Lankan society does not have pleasant attitudes towards construction-related occupants as it is predominantly a blue-collar job (ILO, 2017). This attitude and the educational system do not motivate the construction-related occupants (Akomah, et al., 2020). Skill shortage has a notable influence on the performances in the construction industry as the capacities of trained occupants coming out of training institutions does not meet industry requirements (Manoharan et al., 2020). Because of demographic changes, career expectations of the upcoming generation, the education system of the country, cyclic nature of construction industry resulting variation in demand for skills, rapid changes of technology requiring new skills, the growth of self-employment, the fragmentation of the industry, deteriorating and not updating the in the construction training process, skill drain/emigration, negative social attitude towards the industry, fewer wages, wastage of female skills without contributing to the industry, shifting of the career for another profession due to dissatisfaction, less work experience and inadequate training provided by companies and the inadequate number of trained personnel coming out from training institutions and joining with the labor market, the shortage of numbers of occupants and skill shortage can be captured in the construction industry (Akomah et al., 2020).

\subsubsection{Human Capital Shortage in P\&E Operator}

A shortage implies a disequilibrium situation in which the demand for labor by an employer or group of employers is more than the supply of available workers at the prevailing market wage (Pathirana, 2021). Silva et al. (2018) has suggested the construction companies have to adapt an extended coherence strategy for the issue of shortage of people in overall construction industry. Pathirana (2021) emphasized that most of the Sri Lankan workers are switching among broad fields in construction industry. For an example that study mentioned that a mason very often carries out all the work related to their trade, such as brick laying, concreting, plumbing, plastering, tiling, scaffolding and even bar bending. Nevertheless, other skilled occupants cannot merely undertake the responsibility of P\&E operator since there should be particular practice and training towards operating those P\&E (Prajeesh \& Sakthivel, 2016). Accordingly, Silva et al. (2018) particularly highlighted that there is a prominent shortage of P\&E operators in Sri Lankan construction industry.

\subsubsection{Skill Shortage in P\&E Operators}

Skill shortages hamper the quality and quantity of the output of any industry (Pathirana, 2021). Therefore, skill shortage does not only have implications to particular industries but also to the economy and social aspects of a country. Healy, et al. (2011, p.20) explained that "skill shortages are a complex labor market phenomenon and the most businesses address skill shortages through better utilization of their core workforce, while some employ peripheral strategies". Moreover, Silva et al. (2018,p.78) defined the skill shortage as "a shortage of workers in a particular occupation, labor demand exceeds the availability of skills, or workers lack appropriate qualifications". Accordingly, as P\&E operators have to encompass special skills to handle and operate particular P\&E, the sector of P\&E operators are vulnerable to fall into the status of skill shortage (Naskoudakis \& Petroutsatou, 2016; Pathirana, 2021; Silva et al., 2018). Skill shortage in P\&E operators reduces the productivity and the quality of the building construction project (Akomah et al., 2020). Silva et al. (2018) identified that training and retraining would be the obvious answer for the issue of skill shortage. Accordingly, P\&E operators should be well trained, knowledgeable and better equipped to perform the assigned tasks. 


\section{Methodology}

Saunders, et al (2019) have identified that the qualitative approach can be adopted where the ideas, experiences, beliefs, and attitudes of a specific group of individuals are to be investigated. Furthermore, it is also appropriate for research on emerging concepts through in-depth studies. Semi-structured interviews enable the researcher to address ambiguous responses and verify that the questions and answers are understood correctly (Sekaran, 2003). Hence, the semi-structured interview methodology was adopted as the most acceptable method for data collection for this study. Moreover, Tongco (2007) stated purposive sampling is most effective if the study is about a certain domain that has to study with experts within it. According to Tashakkori and Teddlie (2003, p.713), purposive sampling involves selecting respondents "based on a specific purpose rather than randomly". Thus, the interviewees for this study were selected based on their experience in recruiting and effective management of P\&E operators working in the construction site. Professionals who have experience in that context were selected for the interviews. The profile of interviewees is given in Table 1. A semi structured interview guideline was used to collect information about the research's main topics. The findings of the semi-structured interviews were analysed using the manual content analysis approach.

\begin{tabular}{|l|l|l|}
\hline Interviewee Code & Designation & Experience \\
\hline IE1 & Project Manager & 25 Years \\
\hline IE2 & Senior Mechanical Engineer & 20 Years \\
\hline IE3 & Project Manager & 30 Years \\
\hline IE4 & Senior Civil Engineer & 25 Years \\
\hline IE5 & Chief Quantity Surveyor & 27 Years \\
\hline IE6 & Project Manager & 25 Years \\
\hline
\end{tabular}

Table 1. Profile of Interviewees

\section{Research Findings}

\subsection{OCCUPATIONAL MAP FOR PLANT AND EQUIPMENT OPERATORS IN BUILDING CONSTRUCITONS}

The respondents were questioned regarding the existing categorization of P\&E operators in Sri Lankan construction industry. All the respondents stated that basically P\&E can be divided in to two categories namely "immovable (or fixed)" and "movable". According to IE1, almost all the "immovable" types would be mainly plant while "movable" types can be considered as plant, machineries, equipment and vehicles. Moreover, majority of respondents emphasised that plant exist under the "fixed" type are using for the manufacturing purposes, which would be producing some construction materials such as concrete, asphalt etc. Accordingly, P\&E operators mainly categorised as "fixed plant operators" and "movable plant and equipment operators".

The study revealed that, asphalt plant, batching plant, crusher plant and sand feeding machine are the common immovable plant types used in building construction projects in Sri Lanka. As per the respondents' view, separate operators are assigned for each plant during the construction. Moreover, all respondents mentioned that many of the operators are coming under "movable" type P\&E. According to the respondents, eight (08) main movable P\&E categories identified such as lifting equipment, piling machines, compressors, compacting equipment, earth moving equipment, cranes, generators, and vehicles. Under the crane operators, most of the respondents highlighted that tower crane operators, mobile crane operators and signal control operators can be identified. Other than that, IE3 pointed out that crawler cranes also need to be included under the aforementioned category.

Most of the respondents highlighted that excavator operators, loader operators, dozer operators, and backhoe operators are coming under the earth moving equipment category. Additionally, IE1 pointed out that motor grader operators are also coming under the above category. IE2 mentioned that hydraulic tire excavator operators, mini excavator operators, and long arm excavator operators are coming under excavator operator's category. Moreover, IE4 stated medium long arm is also can be considered as an excavator category. According to IE3 and IE6, wheel loader and truck loader are main loader types. Under the piling machine operators, bored piling equipment operators, pile hammer operators, and pneumatic braker operators were identified by IE6. 
All the respondents highlighted that vehicle operators can also be categorised under the "movable" category and can be further grouped as heavy vehicle operators and light weight vehicle operators. According to IE1, IE3, and IE4, concrete truck operators, concrete pump operators, and pump truck operators have been categorised under the heavy vehicle operators. Other than that, IE2 and IE5 mentioned that lorry drivers and tractor drivers also required to be included under the heavy vehicle category. Additionally, IE6 highlighted that personal transport vehicles which have more than seven seaters been also included in to this category. Furthermore, IE6 pointed out that personal transport vehicle drivers such as cars, single cab, and crew cab (minimum six persons) are come under the lightweight vehicle operators. Some respondents highlighted that hoist and gondolas are example for lifting equipment and separate operators have been assigned for each equipment. Other than that, IE6 pointed that forklift operators and scissor lift operators are also categorised under the lifting equipment operators. IE1 and IE4 described two types of hoist operators such as material hoist operators and passenger hoist operators. Generator operators were also categorised under the movable P\&E. IE4 highlighted the air compressor operators under the compressor operators. IE3 and IE5 identified roller operators, plate compactor operators and tamping rammer operators with respect to the compacting equipment operator's category. Based on the respondents' views and literature findings, occupational map was developed and further validated through three respondents (IE, IE2 and IE5) who involved during the first phase. Figure 1 illustrates the validated occupational map developed for P\&E operators in building construction industry.

\subsection{SKILLS AND COMPETENCIES EXPECT FROM PLANT AND EQUIPMENT OPERATORS}

The respondents highlighted that several skills and competencies are expected from P\&E operators in building construction. Considering the major two categories of "fixed" and "movable" P\&E operators, IE1, highlighted that the importance of technical and mechanical skills respective to both categories. Moreover, IE2 stressed that when considering the fixed plant operators, they are essentially to have more "technical skills" rather than "mechanical skills" since they do not require to know comprehensively about mechanical status of the plant such as required load to be assembled with particular plant, equipment or required electrical voltage in particular equipment etc. In addition, IE4 indicated "technical skills" as one of the major skills required for P\&E operators. More comprehensively, IE2 and IE5 also stated that several technical aspects where knowledge on equipment handling is essential both in practical and theoretical means.

In the sense of "movable" plant operators, IE6 highlighted the necessity of both mechanical and technical skills for crane operators, earth moving operators, compressor operators, generator operators and lifting equipment operators. More comprehensively, IE1 stressed "most of the movable plant and equipment operators are dealing with both technical requirements such as how to handle or operate the plant or equipment and mechanical requirements such as mechanical repairing, loads and voltages requirement etc". As per the opinion of IE2, technical knowledge is essential to handle piling machineries. For an example, a particular operator is required to identify some technical aspects such as the depth of hard rock, expecting resistance from the machine, etc. Hence, requirement of both "technical skills" and "mechanical skills" have been highlighted by all the respondents in generally.

In addition, IE3 stated that generally a performance evaluation is conducting to evaluate several skills under the certain criteria of P \& E operators irrespective of "fixed" and "movable" nature of plant and machineries. According to IE5, under the technical skills, "maintenance skills", and "punctuality" are necessary for P \&E operators since the aforementioned operators are frequently dealing with machineries. Further, IE1 highlighted the importance of having "preventive maintenance skills", since it helps during a breakdown assisting maintenance technicians to resolve equipment, plant and vehicle issues. Majority of the respondents pointed out that the "health and safety skills" are also necessary for P\&E operators in the construction industry since they are frequently working within a high risky operational environment with many of the safety hazards. Additionally, as stated by IE3, basic "information technology (IT) skills" are essential since new machineries emerging in the field are equipped with some sensors and circuits. However, IE4 highlighted "IT skills are not necessary to be embedded within the operators but anyhow, those skills are required to some extent to sustain the operators within the industry with the technology improvement". According to IE5, global construction industry is already equipped with sophisticated technologies. Hence, IE5 stated that IT skills would be compulsory for P\&E operators since very sophisticated P\&E, which are connected with the computers and software will be emerging quickly within the Sri Lankan construction industry. 


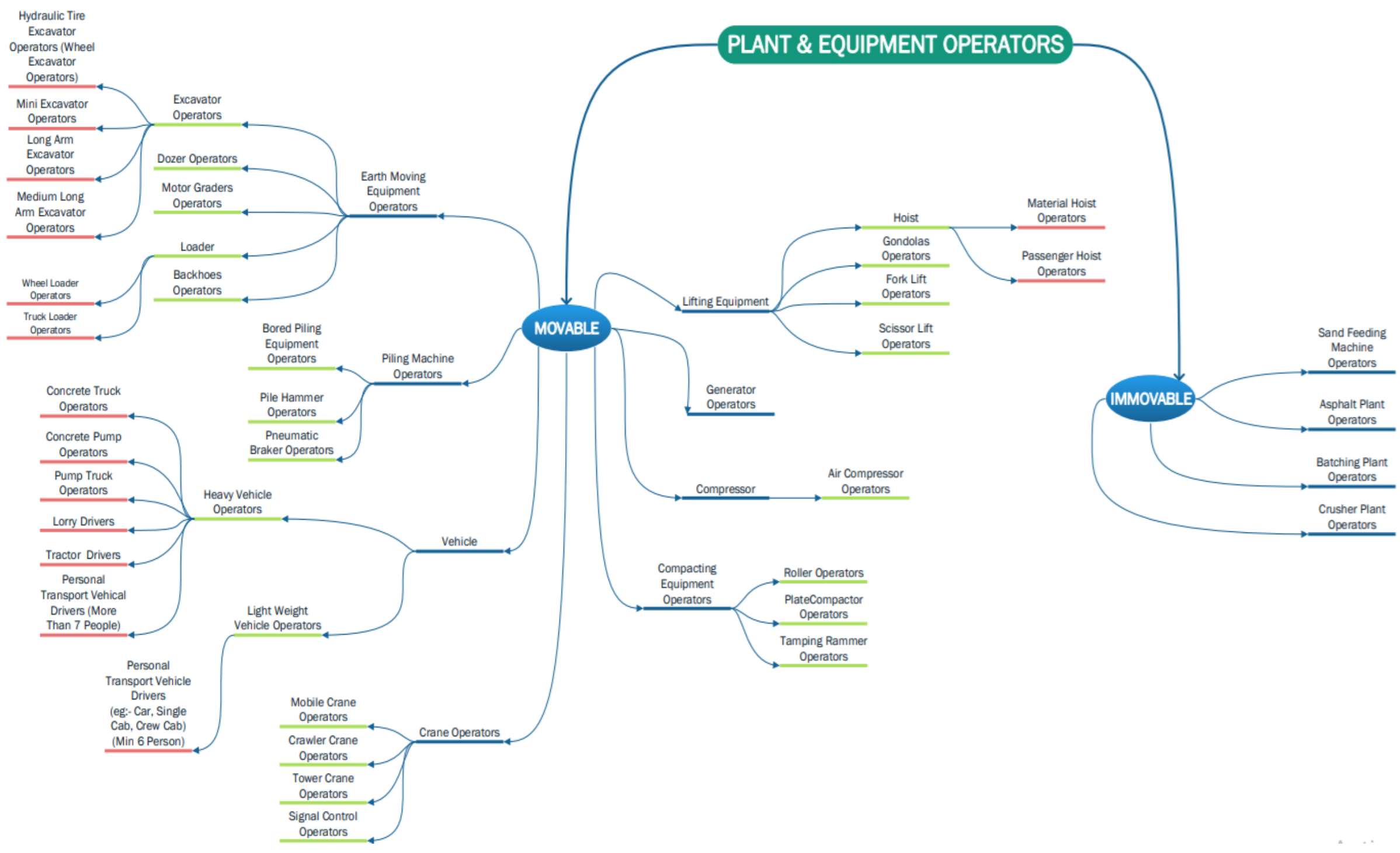

Figure 1: Occupational Map for Plant and Equipment (P\&E) Operators in Building Construction 
Other than the aforementioned skills with respect to the technical skills, majority of the respondents highlighted the necessity of some generic skills for P\&E operators. Accordingly, IE5 stressed the importance of "literacy and numeracy skills" to some extent as they need to proceed with record keeping and filling the forms related to performance within day to day working environment. Furthermore, IE4 explained that "planning skills" are also required to some extent. Planning the felt capacity load for the tower crane, and planning rock bed depth for the piling equipment etc are some of the examples for the aforementioned planning skills of P\&E operators. Moreover, some of the respondents highlighted that "basic English knowledge" is also required to be sustained within the construction industry in the near future. According to IE2, "organizing skills" and "problem-solving skills" are other skills required for operators in since they are working in very challenging environment, which is full of risks and unexpected working conditions. Further, IE2 highlighted that "documentation skills" is an important skill type, which P\&E operators need to be developed along with their experiences within the industry since these skills are not inherited within operators in general practices. According to IE3, "since operators are dealing with large number of employees within the industry in day-to-day operations, it is essential for them to be shaped with communication skills to deal with other employees. Accordingly, the requirement of "communication skills" for P\&E operators highlighted by the respondents.

More comprehensively some respondents have highlighted, specific skills and competencies, which required to be developed according to the type of P\&E. IE1 stated, tower cranes are assembled upon four jacks, hence the load resistance is knowledgeable since the weight are assembling in the front and weight is coming from front jacks". the same idea was highlighted by the IE2 as well with respect to the crane operators. As mentioned by respondents, the tower crane operators are essential to have analytical skills to identify, how much weight can be placed in, which particular location of tower crane etc. According to IE3, "electronic skills are required for compacting operators since most of the machineries coming into operations in the future would be electronically equipped with some devices such as sensors and electronic circuits".

Other than the aforementioned skills, some of the competencies such as "proper ethical behavior" to protect the working environment, "smartness of handling the machines" including the extent of performance within the particular time period and, "higher productivity"," planning skills" have been highlighted by some of the respondents, which are needed to be inculcated with the P\&E operators. Other than that, they need to have social skills as they have to work as a team". According to the interview findings, following skills and competencies are expected from P\&E operators in building construction projects.

Technical skills
Mechanical Skills
Maintenance skills
Analytical Skills
Preventive maintenance skill
Problem-solving skills
Interpersonal skills

Technical skills

Mechanical Skills

Maintenance skills

Preventive maintenance skill

Interpersonal skills

\author{
Health and safety skills \\ IT skills \\ Organizing skills \\ Problem-solving skills \\ Documentation skills \\ Electronic skills \\ Language literacy
}

\author{
Punctuality \\ Communication skills \\ Proper ethical behaviour \\ Planning skills \\ Smartness of handling the machines \\ Teamwork \\ Numeracy skills
}

\subsection{EXISTING ISSUES EXPERIENCE WITH PLANT AND EQUIPMENT OPERATORS}

When considering the existing issues that are experiencing from the P\&E operators, several issues have been identified by the respondents in many aspects. All the respondents signified the "lack of reliability" of the P\&E operators due to aging of those employees. Further, IE2 highlighted some issues due to old aged people are working in many construction sites, such as they tend to take long vacations and not continuing works, poor health condition of the workers and difficult to resist within the industry. Moreover, IE1 mentioned "due to the nature of lower-level salary of these workers and not upgrading, the motivation level of P\&E operators is considerably decreasing. Also, some of the operators are in the nature of lesser experience gaining". Accordingly, "lack of motivation" and "less experience gaining" can be highlighted as some of the major issues that are experiencing from P\&E operators. In this sense IE1 highlighted that newly employed operators need to be more technologically improved since the required level of knowledge is not enough due to less experience.

According to IE5, in Sri Lanka, there are lesser number of operators who have multiple skills to handle different machineries, compared to the global construction industry. At this point, a scheme must be developed to build the multi skill workers. Hence, "lack of multiskilled workers" was highlighted as 
another issue in the existing workforce under P\&E operators by majority of the respondents. According to IE1, IE3, and IE4, the practical skills are lesser with the recently recruited operators due to most of the academic sessions are continuing through online mode. Therefore, the practical lessons conducted are significantly lesser and the newly recruited operators are not having sufficient practical knowledge. Accordingly, "lack of practical skills" has become a considerable issue with the recently recruited operators in the industry. As per IE2 and IE5, due to several social issues, these operators are not sustaining in the field, most of the people are trying to move on to white collar jobs and therefore, few people are coming to the construction industry as the P\&E operators. Therefore, it is evident that "lack of sustaining in the industry" has become another major issue related with the P\&E operators. Further, IE4 evident this issue as "at the national level there are no proper government plans to train the P\&E operators. The government give the priority to Engineers, Doctors, and Quantity Surveyors etc, but not to for the lower-level employees, therefore they are not sustaining in the field". Furthermore, IE4 described that there must be a vocational training facility, accreditation, graduation levels which will motivate the employees to be sustained in the field. Anyhow, according to the respondents, there are no proper training institutions, monitoring procedure, and certificate awarding institutions. According to IE4, "as far as the policy level are the problems. At the same time, there are no proper promotions from the government, no proper categorisation, and also less respect for the P\&E operators in the construction industry".IE2, IE5 and IE6 stated that the main problem in construction sites is the "unavailability of experienced operators". More comprehensively, the respondent expressed that the fresher operators are getting trained under senior operators. and there are several conflicts between the senior operator and the trainee operator and sometime the trainee operators are not getting any support. So, there is no proper way to give training sessions for the fresher operators". Other than that, "lack of social recognition", "unavailability of dignity", and "unavailability of proper hierarchy for promotions" for the operators can be identified as some of the other major problems for the P\&E operators in the building construction industry highlighted by the majority of the respondents.

The summary of the above identified findings related to the existing issues, which can be experienced with the plant and equipment operators has been elaborated in Table 2 .

\begin{tabular}{|c|c|c|c|c|c|c|}
\hline Existing Issues of Plant \& Equipment Operators & IE1 & IE2 & IE3 & IE4 & IE5 & IE6 \\
\hline Lack of reliability & $\mathrm{X}$ & $\mathrm{X}$ & $\mathrm{X}$ & $\mathrm{X}$ & $\mathrm{X}$ & $\mathrm{X}$ \\
\hline Lack of motivation & $\mathrm{X}$ & $\mathrm{X}$ & & $\mathrm{X}$ & & \\
\hline Less experience gaining & $\mathrm{X}$ & $\mathrm{X}$ & & & $\mathrm{X}$ & \\
\hline Lack of multiskilled workers & $\mathrm{X}$ & & $\mathrm{X}$ & $\mathrm{X}$ & $\mathrm{X}$ & $\mathrm{X}$ \\
\hline Lack of practical skills & $\mathrm{X}$ & & $\mathrm{X}$ & $\mathrm{X}$ & & \\
\hline Lack of sustaining in the industry & & $\mathrm{X}$ & & $\mathrm{X}$ & $\mathrm{X}$ & \\
\hline Unavailability of experienced operators & $\mathrm{X}$ & $\mathrm{X}$ & & & $\mathrm{X}$ & $\mathrm{X}$ \\
\hline Lack of social recognition & $\mathrm{X}$ & & $\mathrm{X}$ & $\mathrm{X}$ & $\mathrm{X}$ & \\
\hline Unavailability of dignity & & $\mathrm{X}$ & $\mathrm{X}$ & & $\mathrm{X}$ & $\mathrm{X}$ \\
\hline Unavailability of proper hierarchy for promotions & $\mathrm{X}$ & & $\mathrm{X}$ & $\mathrm{X}$ & $\mathrm{X}$ & $\mathrm{X}$ \\
\hline
\end{tabular}

Table 2. Summary of existing issues of plant and equipment operators

\section{Conclusions}

P\&E operators play an important role within Sri Lankan construction industry, as there are different and advanced P\&E are used in a larger scale project or even in a small scale. However, there is not any significant study, which has focused on this occupation category and address its drawbacks. Therefore, this study successfully addressed three (03) main objectives namely development of occupational map, identifying skills, and issues of P\&E operators in Sri Lankan building construction industry. The operators have been categorised under two main categories as "fixed plant operators" and "movable P\&E operators". Then subcategories were identified and based on that the occupational map was developed for the P\&E operators in the building construction industry. Moreover, the list of skills and competencies expected from P\&E operators were discovered. It has been identified that fixed plant operators have to be equipped with more "technical skills" rather than "mechanical skills" where both skills equally required for the movable P\&E operators. In addition, less consistency, taking long vacations and not continuing the works, poor health conditions, lower salary range, lesser motivations, lack of experience have been identified as prominent issues relating to the P\&E operators in Sri Lankan building construction industry. Further, it has been emphasised those operators do not sustain in the industry due to that the lesser priority to lower-level employees and absence of structured and regulated training program. Therefore, further research can be conducted to analyzing the skills gap of P\&E operators and proposing strategies to sharp the skills of P\&E operators to overcome existing issues in the Sri Lankan building construction industry. 


\section{Acknowledgement}

The authors wish to acknowledge the support from the Senate Research Committee of University of Moratuwa under the Grant SRC/ST/2021/06.

\section{References}

Aiyetan, O. A., and Dillip, D. 2018. System dynamics approach to mitigating skilled labour shortages in the construction industry: A South Africa context. Construction Economics and Building, 18(4), 4563. https://doi.org/10.5130/ajceb.v18i4.6041

Akomah, B., Ahinaquah, L., and Mustapha, Z. 2020. Skilled labour shortage in the building construction industry within the central region. Baltic Journal of Real Estate Economics and Construction Management, 8(1), 83-92. doi:10.2478/bjreecm-2020-0005

Alaghbari, W., Al-Sakkaf, A., and Sultan, B. 2019. Factors affecting construction labour productivity in Yemen. International Journal of Construction Management, 19(1), 79-91. doi:10.1080/15623599.2017.1382091

Anuruddika, N., and Sandanayake, Y. 2015. An investigation into skilled labour requirement in Sri Lankan building construction industry. Retrieved from http://dl.lib.mrt.ac.lk/handle/123/11202

Basnayake L.K. and Premathilaka R.P.M.M. 2015. Shortage of skilled labour in construction industry of Sri Lanka. http://www.bing.com. Accessed 10.11.2016.

Ceric, A., and Ivic, I. 2020. Construction labor and skill shortages in Croatia: Causes and response strategies. Organization, Technology and Management in Construction: an International Journal, 12(1), 22322244. https://doi.org/10.2478/otmcj-2020-0019

Central Bank of Sri Lanka. 2019. National output, expenditure and income - 2018. Colombo 1: Central Bank of Ceylon.

Chandasiri, S. 2017. An assessment on skills needs and skills gap in construction industry. Sri Lanka: Ministry of Skills Development and Vocational Training [MSDVT].

Detsimas, N., Coffey, V., Sadiqi, Z., and Li, M. 2016. Workplace training and generic and technical skill development in the Australian construction industry. Journal of management development, 35(4), 486-504. doi:10.1108/JMD-05-20150073

Feng, Y., Zhang, S. and Wu, P., 2015. Factors influencing workplace accident costs of building projects. Safety science, 72 , pp.97-104.

Fernando, P., Fernando, N., and Gunarathna, M. 2016. Skills developments of labourers to achieve the successful project delivery in the Sri Lankan construction industry. Civil and Environmental Research, 8(5), 86-97. Retrieved from http://nrl.northumbria.ac.uk/id/eprint/31127/3/30376-33213-1-PB.pdf

Frankel, J. 2003. Backhoe kinematics \& dynamics. Available from: http://imdl.gatech.edu/jfrankel/docs/Kin-Dyn.pdf .html

Gurmu, A. T., and Aibinu, A. A. 2017. Construction equipment management practices for improving labor productivity in multistory building construction projects. Journal of Construction Engineering and Management, 143(10), 04017081. https://doi.org/10.1061/(asce)co.1943-7862.0001384

Healy, J., Mavromaras, K., and Sloane, P. 2011. Adjusting to skill shortages: complexity and consequences. Retrieved from http://hdl.handle.net/10419/58729

International Labour Organisation. 2017. Labour market trends \& skills profiles of Sri Lankan migrant workers in the construction industry in GCC countries. International Labour Organisation.

Jayawardena, H., Senevirathne, K., and Jayasena , H. 2008. Skilled Workforce in Sri Lankan construction industry: production vs. acceptance. Post disaster recovery challenges in Sri Lanka, 27.

Kamaruddin, S., Mohammad, M., and Mahbub, R. 2016. Barriers and impact of mechanisation and automation in construction to achieve better quality products. Procedia-Social and Behavioral Sciences, Procedia-Social and Behavioral Sciences, 111-120. doi:10.1016/j.sbspro.2016.05.197

Komissarov, A.P., Lagunova, Y.A. and Lukashuk, O.A. 2016. Evaluation of single-bucket excavators energy consumption. Procedia Engineering, 150:1221-1226. doi:10.1016/j.proeng.2016.07.239

Manikandan, M., Adhiyaman, M., and Pazhani, K. 2018. A Study and analysis of construction equipment management used in construction projects for improving productivity. International Research Journal of Engineering and Technology. Technol., 5, . International Research Journal of Engineering and Technology, 5(3), 1297-1303. Retrieved from https://d1wqtxts1xzle7.cloudfront.net/56785527/IRJET-V5I3294.pdf?1528862944=\&response-contentdisposition=inline\%3B+filename\%3DA_STUDY_AND_ANALYSIS_OF_CONSTRUCTION_EQU.pdf\&Expires=1626122 287\&Signature=Vo1jlv54BGGKx8q53wkXTGoaz eOFTvKKXhrZnhJDZCTZFKCWQrnSK

Manoharan, K., Dissanayake, P., Pathirana, C., Deegahawature, D., and Silva, R. 2020. Assessment of critical factors influencing the performance of labour in Sri Lankan construction industry. International Journal of Construction Management, 1-35. doi:10.1080/15623599.2020.1854042.

Naskoudakis, I., and Petroutsatou, K. 2016. A thematic review of main researches on construction equipment over the recent years. Procedia Engineering, 164, 206-213. https://doi.org/10.1016/j.proeng.2016.11.611 
Pathirana, L. 2021. Construction Industry and Factor Condition Prospective of Sri Lanka: A Special Reference to Skill Labour Shortage. IOSR Journal of Business and Management, 23(2), 35-41. doi:10.9790/487X-2302073541

Prajeesh. V. P., and Sakthivel,N.2016. 'Management of Equipment \& Machinery in Construction. International Journal of Innovative Science, Engineering \& Technology, 6(3), 2016, pp.113-118.

Saunders, M., Lewis, P., and Thornhill, A. 2019. Research Methods for Business Students (8th ed ed.). UK:Pearson.

Sekaran, U. 2003. Research methods for business: A skill building approach (4th ed.). New York: John Wily \& Sons.

Silva, G., Warnakulasuriya, B., and Arachchige, B. 2018. A review of the skill shortage challenge in construction industry in Sri Lanka. International Journal of Economics, Business and Management Research, 2(1), 75-89.

Taofeeq, D., Adeleke, A., and Ajibike, W. 2020. Human factors influencing contractors' risk attitudes: A case study of the Malaysian construction industry. Construction Economics and Building, 20(1), 96-116. doi:10.5130/AJCEB.v20i1.6735

Tashakkori, A., and Charles, T. 2003. Issues and dilemmas in teaching research methods courses in social and behavioural sciences: US perspective. International journal of social research methodology, 6(1), 61-77.

Tongco, M. 2007. Purposive sampling as a tool for informant selection. Ethnobotany Research and applications, 5, 147158. 